\title{
Do pingers reduce interactions between bottlenose dolphins and nets around the Balearic Islands?
}

\author{
José María Brotons ${ }^{1}$, Zaida Munilla ${ }^{1}$, Antonio María Grau ${ }^{1}$, Luke Rendell ${ }^{2, *}$ \\ ${ }^{1}$ Office of Fisheries Management, Government of the Balearic Islands, Foners 10, Palma de Mallorca 07006, \\ Balearic Islands, Spain \\ ${ }^{2}$ Sea Mammal Research Unit, School of Biology, University of St. Andrews, Fife KY16 8LB, UK
}

\begin{abstract}
The artisanal gillnet fishery around the Balearic Islands is experiencing a growing problem with bottlenose dolphins Tursiops truncatus depredating the bottom-set nets. The resulting catch loss engenders hostility from fishers, and interactions between dolphins and nets can result in bycatch mortality. One potential mitigation measure is the placement of acoustic alarms, or pingers, on the nets. However, as pingers have produced mixed results in studies of their effectiveness in other fisheries, direct evidence is needed on whether they will be effective in this fishery. We report on a large-scale experimental trial in which 59 different vessels from the artisanal fleet were each equipped with identical nets, and each vessel was assigned to 1 of 3 conditions: no pinger, inactive pinger or active pinger. Three brands of pinger were tested. During the trial, data on fishing operations were recorded by onboard observers. A total of 1193 fishing operations were observed. We analysed 2 response variables, the presence or absence of evidence that dolphins had interacted with the net, and standardized yields, using generalized linear mixed models. Overall net interaction rates were reduced by $49 \%$ with active pingers, but not all pinger brands were equally effective. Yields, measured as profit per unit effort, were increased by $9 \%$ in the active-pinger condition, but this was not statistically significant $(\mathrm{p}=0.592)$. Our results suggest that pingers in the artisanal fisheries of the Balearic Islands reduced the rate of net interaction, but further study is required given dolphins' potential for habituation.
\end{abstract}

KEY WORDS: Pingers $\cdot$ Gillnet $\cdot$ Bottlenose dolphin $\cdot$ Bycatch $\cdot$ Balearics

\section{INTRODUCTION}

Mortality from bycatch is a serious problem for many marine mammal populations and substantial management effort is directed at mitigating this source of mortality. Gillnet fisheries are a major source of such mortality for small cetaceans (Perrin et al. 1994). Acoustic deterrent devices such as pingers have attracted much attention as a possible way to mitigate these problems, but data on their effectiveness is relatively sparse, despite their widespread use (Jefferson \& Curry 1996). The last decade has seen an increased research effort on the effectiveness of pingers, and results suggest that effectiveness may vary widely between species, fishing areas and fisheries. Effort initially focussed on the harbour porpoise Phocoena phocoena and there is some good evidence that pingers may be effective for this species. Kraus et al. (1997) showed, using a powerful double-blind experimental design, that pingers reduced harbour porpoise bycatch in the USA Gulf of Maine gillnet fishery by an order of magnitude, leading to widespread use of pingers in fisheries with porpoise bycatch problems. More recently, Culik et al. (2001) showed experimentally that pingers can exclude harbour porpoises from the area around an experimental float line, increasing median approach distance from 150 to $530 \mathrm{~m}$. Carlström et al. (2002) tested whether pingers reduced harbour porpoise bycatch in an active gillnet fishery in the Swedish Skagerrak Sea, comparing nets with inactivated 
(referred to henceforth as inactive) and activated (active) pingers attached. They observed no porpoise mortality in either active or inactive nets, when previous bycatch rates would have predicted at least 7 individuals. Either a multi-year study or control nets with no pingers attached would be needed to clarify whether pinger presence alone reduced bycatch, or whether the reduction in bycatch was mediated by inter-annual variation in porpoise density. Therefore, Carlström et al.'s (2002) results are equivocal, and the effectiveness of pingers in this fishery remains unknown.

Results are also varied for other small cetacean species. Experimental studies have shown that species vary in their response to the same stimuli. For example, captive striped dolphins Stenella coeruleoalba showed no reaction to pingers, while harbour porpoises produced strong behavioural responses in the same conditions, despite the pingers being audible to both species (Kastelein et al. 2006). Field studies have produced mixed results. Cox et al. (2003) found no difference in the behaviour of bottlenose dolphins Tursiops truncatus around a pinger-equipped gill net whether the pingers were active or inactive, although they found a slight reduction in the likelihood of groups approaching to within $100 \mathrm{~m}$ of the centre of the net. Cox et al. (2004) concluded that pingers were 'unlikely to reduce bycatch of bottlenose dolphins in gillnet fisheries.' In contrast, Leeney et al. (2007) observed a marked drop in acoustic detections of bottlenose dolphins around statically moored pingers not associated with a net, although this result could equally represent a decline in dolphin numbers or in vocalisation rates. Finally, Monteiro-Neto et al. (2004) studied the presence of tucuxi Sotalia fluviatilis around experimental pingers deployed on floating lines, and found no clear reduction in animal presence associated with active pingers. It is possible that pinger studies that are not associated with fishing activity may not readily generalise to active fisheries because a major motivation factor leading animals to approach nets is missing - the presence of prey fish.

In contrast, some studies in active fisheries have provided evidence that pinger use does reduce cetacean bycatch. For example, Bordino et al. (2002) used a robust double-blind experimental protocol and demonstrated that pingers significantly reduced mortality of Franciscana dolphins Pontoporia blainvillei in a bottom-set gillnet fishery in Argentina. Similarly, Barlow \& Cameron (2003) studied pingers experimentally in an active Californian drift gillnet fishery and showed that bycatch rates for common dolphin Delphinus delphis were reduced by $85 \%$ when pingers were used.

The main conclusion from these studies is that while there is good evidence that pingers can be effective in reducing bycatch for some cetaceans, there is no definitive answer as to whether pingers are an effective mitigation measure for all small cetacean bycatch; results depend on the species, area, and fishery in question (Dawson et al. 1998). A further issue is habituationan initially aversive response to the sound of pingers may wear off over time (Jefferson \& Curry 1996, Dawson et al. 1998, Cox et al. 2004). Even in harbour porpoises, effectiveness may decline rapidly with continued exposure (Cox et al. 2001). Pingers may even become positive stimuli, acting as a 'dinner bell' for the focal or other species (e.g. Bordino et al. 2002). There is, however, still very little information available on the importance of habituation effects with respect to bycatch mitigation by pingers. These considerations mean that fishery managers will require evidence of pinger effectiveness in their particular fishery when making decisions on bycatch mitigation policies.

In 2005, the Balearics artisanal fishing fleet comprised 296 small (5 to $9 \mathrm{~m}$ ) vessels, directly employed ca. 500 people and landed a total catch valued at ca. $€ 3371000$ (Brotons et al. 2007). The fishery is diverse, landing dozens of species, and using bottom-set trammel and gill nets. In recent years, this fishery has experienced problems relating to interactions between nets and dolphins in terms of fish loss, net damage and bycatch. We recently estimated that these interactions represented an economic cost, from fish loss and net damage, of $6.5 \%$ (95\% CI: 1.6 to $12.3 \%$ ) of the total landed catch value (Brotons et al. 2007). Although the loss is not large, the perception of it is large enough for some fishers to call for dolphins to be culled. Furthermore, bycatch mortality may reach between 30 and 60 dolphins annually, although there are no reliable current estimates (for more information see Brotons et al. 2007). In the present study we report the results of a large-scale experimental study of pinger effectiveness in this active fishery.

\section{MATERIALS AND METHODS}

The study was conducted in the coastal waters of the Balearic Islands, in depths of up to $60 \mathrm{~m}$ (Fig. 1). The experiment used 59 different vessels from the artisanal fleet, each equipped for the study with identical experimental nets. Data on fishing activities were recorded by onboard observers, who rotated between vessels during the study period. Each time a net was hauled, observers used standardised forms to record the location, weather conditions, and details of the catch (the weight in $\mathrm{kg}$ of each species caught). We subsequently combined these data with local market prices, collated by the Office of Fisheries Management, to produce a measure of the yields, in this case gross profit per unit 
effort (PPUE), expressed as Euros per $50 \mathrm{~m}$ net set (see Brotons et al. 2007). Observers also noted the presence or absence of evidence of dolphin interaction with the net; this could be either a visual sighting of dolphins around the net (within $500 \mathrm{~m}$ of the vessel), or the presence of characteristically damaged fish (for more details see Brotons et al. 2007). Vessels were assigned randomly to 1 of 3 experimental treatments experimental conditions: control (no pingers), inactive pingers (deployed on net but not transmitting) and active pingers (deployed and transmitting). The artisanal fleet is organised into local 'cofradias', or cooperatives, with responsibility for a certain geographic area surrounding a given port. Although vessels were assigned to treatments at random within cooperatives, treatments were distributed as equally as possible across localities to minimise the effect of geographic area, as we have previously found net interactions rates to vary considerably across areas (Brotons et al. 2007). When pingers were present, both observers and fishers were blind as to whether these were active or not, as the pingers were activated by saltwater switches once immersed. Three brands of pinger were used: Aquatec AQUAmark ${ }^{\circledR} 210$ (wide-band, 'extrarandom' frequency modulation, $155 \mathrm{~dB}$ re $1 \mu \mathrm{Pa}$ at $1 \mathrm{~m}$, 5 to $160 \mathrm{kHz}$ ), Dukane NetMark ${ }^{\circledR} 1000$ (minimum source level $130 \mathrm{~dB}$ re $1 \mu \mathrm{Pa}$ at $1 \mathrm{~m}$, broadband signal up to $10 \mathrm{kHz}$ ), and SaveWave ${ }^{\circledR}$ Dolphinsaver Highimpact (155 dB re $1 \mu \mathrm{Pa}$ at $1 \mathrm{~m}$, frequency modulated sweeps with harmonics, 5 to $160 \mathrm{kHz}$ ). The acoustic properties reported are those given by the manufacturers and we made no attempt to verify their accuracy. Pingers were deployed on the nets in accordance with manufacturers' recommendations.

Since interaction with the net through depredation is a prerequisite for entanglement in it, we used the frequency of net interaction as a measure of bycatch risk, so that our results were not dependent on actual mortality for interpretation. In fact, no dolphins were caught in any of the experimental nets during the study. Nonetheless, any observed reductions in depredation rates are of interest, since they may indicate both reduced economic losses and a lower risk of bycatch.

We analysed the data using generalised linear mixed effects models (Pinheiro \& Bates 2000, Faraway 2006), examining the effects of pinger treatment (absent, inactive or active) and pinger brand on 2 response variables: the presence or absence of evidence that dolphins had interacted with the net and the PPUE. The unit of analysis was the individual fishing operation, i.e. each time the net was set and recovered completely. We used mixed models after preliminary analysis revealed large variation in both response measures among vessels within treatments.
We wanted to include this variation in our analyses because fishing sets by the same vessel could not be considered independent, and because we wanted our inference to be valid for vessels in general, rather than the specific ones chosen for the study as these represent less than one-quarter of the total fleet. Therefore, we included vessel as a random factor in all our models. Pinger treatment was entered as a treatment-coded categorical variable (Fox 2002) with the pinger-absent condition set as the baseline. We coded pinger brand along with pinger treatment as a separate categorical variable (again treatment-coded with pinger-absent as the baseline), combining treatment and type such that this variable had 7 levels: pinger-absent, Aquatec-inactive, Aquatec-active, Dukane-inactive, Dukane-active, SaveWave-inactive, SaveWave-active.

As previous work on this fishery has shown that there is a strong seasonal effect on both dolphin-net interaction rates and PPUE (Brotons et al. 2007), we also tested models including month as a categorical variable. In the case of the first response variable, the presence/ absence of dolphins interacting with the net, we used models of the binomial family with a logit link function. In the case of PPUE, we found that the variance of PPUE values increased with their mean across vessels, so we chose Gamma family models with a log link function. Models were estimated using the 'glm', 'lmer' and 'glmmPQL' functions in the software R (Fox 2002, R Development Core Team 2004, Faraway 2006); details of the exact coding used to fit the models are given in Appendix 1 (available as electronic supplementary material at: www.int-res.com/articles/suppl/ n005p301_app.pdf.

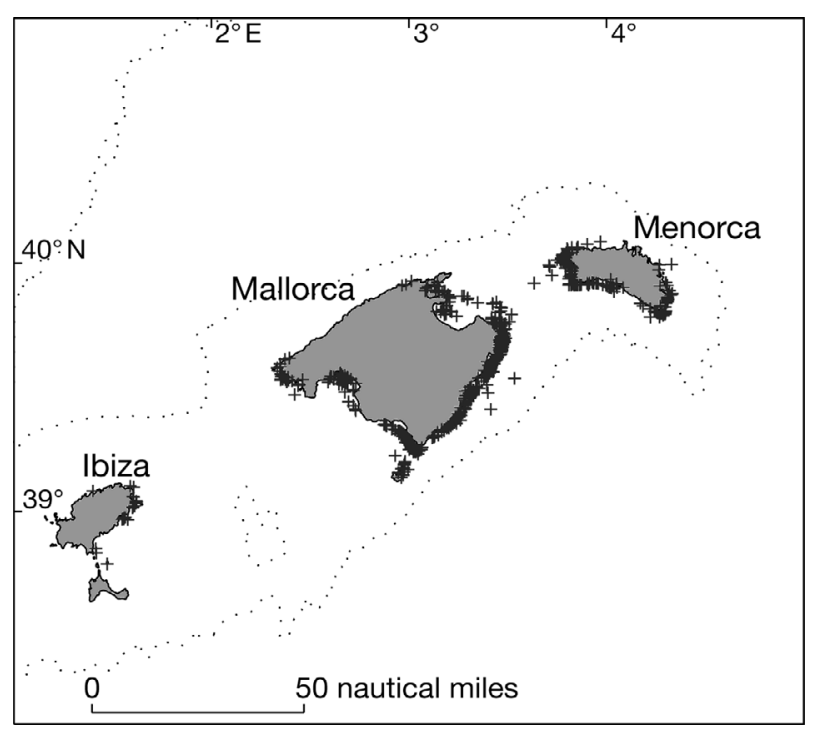

Fig. 1. Locations of fishing operations in the Balearic Islands. Dotted lines show the $1000 \mathrm{~m}$ isobath 
Table 1. Data summary by vessel. For an explanation of 'Condition' see 'Materials and methods'. Values for profit per unit effort (PPUE) are mean (SD). na: not applicable

\begin{tabular}{|c|c|c|c|c|c|c|}
\hline Vessel code & Condition & $\begin{array}{l}\text { Pinger } \\
\text { brand }\end{array}$ & $\begin{array}{c}\text { No. of } \\
\text { sets observed }\end{array}$ & $\begin{array}{l}\text { No. of times } \\
\text { evidence of dolphin-net } \\
\text { interaction observed }\end{array}$ & $\begin{array}{l}\text { Interaction rate } \\
\text { (interaction observed/ } \\
\text { sets observed) }\end{array}$ & $\begin{array}{l}\text { PPUE (gross) } \\
(€ \text { per } 50 \mathrm{~m} \text { net) }\end{array}$ \\
\hline 5 & Absent & na & 22 & 1 & 0.05 & $1.98(1.07)$ \\
\hline 7 & Absent & na & 36 & 1 & 0.03 & $4.24(2.14)$ \\
\hline 17 & Absent & na & 46 & 3 & 0.07 & $1.45(0.98)$ \\
\hline 23 & Absent & na & 13 & 0 & 0.00 & $3.29(2.30)$ \\
\hline 47 & Absent & na & 15 & 2 & 0.13 & $3.91(1.71)$ \\
\hline 50 & Absent & na & 5 & 0 & 0.00 & $3.84(2.00)$ \\
\hline 60 & Absent & na & 7 & 5 & 0.71 & $5.29(2.93)$ \\
\hline 21 & Inactive & Aquatec & 88 & 2 & 0.02 & 1.86 (1.09) \\
\hline 36 & Inactive & Aquatec & 9 & 2 & 0.22 & $0.65(0.57)$ \\
\hline 38 & Inactive & Aquatec & 2 & 0 & 0.00 & $3.00(1.40)$ \\
\hline 54 & Inactive & Aquatec & 19 & 1 & 0.05 & $4.21(2.88)$ \\
\hline 3 & Inactive & Dukane & 11 & 0 & 0.00 & $2.84(1.02)$ \\
\hline 15 & Inactive & Dukane & 32 & 0 & 0.00 & $2.99(1.82)$ \\
\hline 20 & Inactive & Dukane & 15 & 2 & 0.13 & $3.26(2.62)$ \\
\hline 34 & Inactive & Dukane & 16 & 5 & 0.31 & $3.10(2.10)$ \\
\hline 6 & Inactive & SaveWave & 64 & 3 & 0.05 & $4.82(3.16)$ \\
\hline 16 & Inactive & SaveWave & 30 & 1 & 0.03 & $4.57(2.55)$ \\
\hline 30 & Inactive & SaveWave & 20 & 4 & 0.20 & $4.56(2.24)$ \\
\hline 8 & Active & Aquatec & 54 & 5 & 0.09 & $3.94(2.42)$ \\
\hline 9 & Active & Aquatec & 27 & 0 & 0.00 & $1.81(1.22)$ \\
\hline 10 & Active & Aquatec & 17 & 0 & 0.00 & $3.48(2.20)$ \\
\hline 13 & Active & Aquatec & 11 & 0 & 0.00 & $5.14(3.20)$ \\
\hline 14 & Active & Aquatec & 12 & 0 & 0.00 & $2.65(1.40)$ \\
\hline 18 & Active & Aquatec & 10 & 0 & 0.00 & $3.13(1.45)$ \\
\hline 22 & Active & Aquatec & 30 & 1 & 0.03 & $4.86(3.01)$ \\
\hline 26 & Active & Aquatec & 16 & 0 & 0.00 & $5.53(4.61)$ \\
\hline 32 & Active & Aquatec & 3 & 0 & 0.00 & $2.98(0.90)$ \\
\hline 33 & Active & Aquatec & 35 & 0 & 0.00 & $4.42(3.40)$ \\
\hline 40 & Active & Aquatec & 11 & 0 & 0.00 & $2.23(1.07)$ \\
\hline 43 & Active & Aquatec & 28 & 0 & 0.00 & 2.69 (1.75) \\
\hline 52 & Active & Aquatec & 2 & 0 & 0.00 & $1.67(0.44)$ \\
\hline 61 & Active & Aquatec & 4 & 0 & 0.00 & na \\
\hline 4 & Active & Dukane & 13 & 0 & 0.00 & 3.65 (1.23) \\
\hline 11 & Active & Dukane & 35 & 2 & 0.06 & $3.99(2.96)$ \\
\hline 12 & Active & Dukane & 22 & 1 & 0.05 & $4.20(2.05)$ \\
\hline 19 & Active & Dukane & 20 & 0 & 0.00 & $4.49(2.43)$ \\
\hline 24 & Active & Dukane & 17 & 4 & 0.24 & $1.85(1.12)$ \\
\hline 28 & Active & Dukane & 15 & 3 & 0.20 & $3.12(2.08)$ \\
\hline 39 & Active & Dukane & 15 & 0 & 0.00 & $4.30(2.38)$ \\
\hline 46 & Active & Dukane & 25 & 0 & 0.00 & $4.15(1.92)$ \\
\hline 51 & Active & Dukane & 8 & 1 & 0.13 & $5.34(2.50)$ \\
\hline 53 & Active & Dukane & 67 & 2 & 0.03 & $2.13(1.19)$ \\
\hline 56 & Active & Dukane & 13 & 0 & 0.00 & $4.24(3.44)$ \\
\hline 58 & Active & Dukane & 14 & 0 & 0.00 & $3.39(1.52)$ \\
\hline 62 & Active & Dukane & 2 & 0 & 0.00 & $4.14(0.70)$ \\
\hline 63 & Active & Dukane & 6 & 2 & 0.33 & $2.41(0.97)$ \\
\hline 25 & Active & SaveWave & 19 & 1 & 0.05 & $3.78(2.17)$ \\
\hline 27 & Active & SaveWave & 14 & 0 & 0.00 & 3.67 (1.75) \\
\hline 29 & Active & SaveWave & 10 & 2 & 0.20 & $2.03(1.67)$ \\
\hline 31 & Active & SaveWave & 4 & 0 & 0.00 & $2.17(1.26)$ \\
\hline 35 & Active & SaveWave & 44 & 0 & 0.00 & $3.38(1.83)$ \\
\hline 37 & Active & SaveWave & 2 & 0 & 0.00 & $4.40(4.44)$ \\
\hline 44 & Active & SaveWave & 17 & 5 & 0.29 & $6.63(4.00)$ \\
\hline 45 & Active & SaveWave & 19 & 1 & 0.05 & $4.50(3.35)$ \\
\hline 48 & Active & SaveWave & 8 & 0 & 0.00 & $1.31(0.80)$ \\
\hline 49 & Active & SaveWave & 16 & 0 & 0.00 & $1.92(0.53)$ \\
\hline 55 & Active & SaveWave & 3 & 0 & 0.00 & $1.86(0.19)$ \\
\hline 59 & Active & SaveWave & 25 & 0 & 0.00 & $1.83(0.58)$ \\
\hline 64 & Active & SaveWave & 19 & 2 & 0.11 & na \\
\hline 65 & Active & SaveWave & 10 & 0 & 0.00 & 2.39 (1.66) \\
\hline
\end{tabular}




\section{RESULTS}

A total of 1193 sets were observed between July and December of 2005 (Fig. 1). Of these, 144 had no pingers, 306 had inactive pingers (118 Aquatec, 74 Dukane, and 114 SaveWave) and 743 had active pingers (260 Aquatec, 272 Dukane, and 211 SaveWave). Data on the number of sets, the number of times net interaction was observed, and the average PPUE per vessel are listed in Table 1. The overall net interaction rate over the trial was 0.054 , while the rate for the no-pinger control condition was 0.083 . These figures are low compared with previous years; during observational studies in 2001 to 2003 the overall interaction rate for each year ranged from 0.09 to 0.28 (Brotons et al. 2007). Interaction rates for the inactive and active pinger conditions were 0.065 and 0.043 , respectively (Fig. 2).

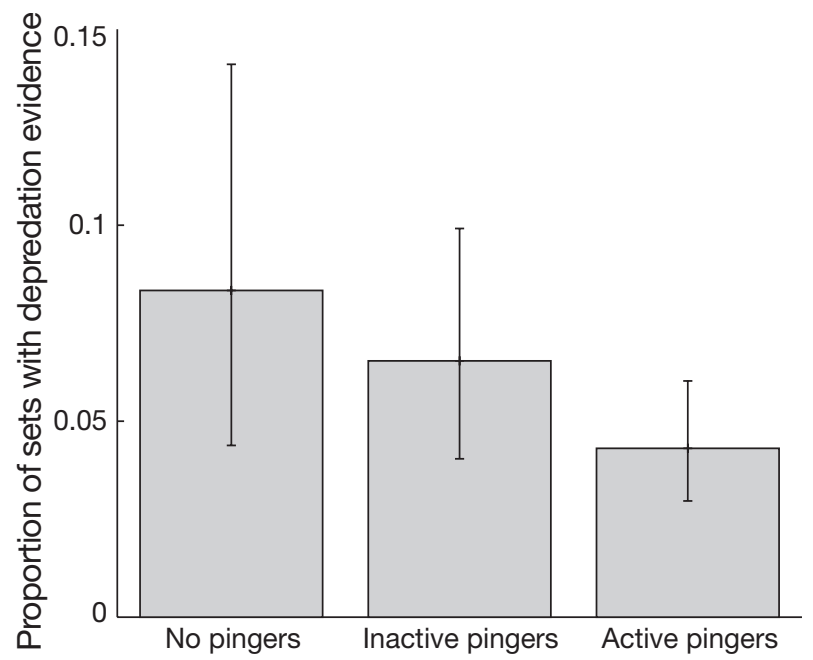

Fig. 2. Net interaction rates for 3 experimental treatments. Error bars are $95 \%$ confidence intervals on the maximum likelihood estimates for the binomial probability of net interaction

Table 2. Coefficients from final model of net interaction with overall pinger treatment. Here the intercept represents the rate of net interaction in MONTH 7 (July) for the no-pinger control condition. Significant pinger terms are highlighted in bold

\begin{tabular}{|lrrrr|}
\hline Term & Estimate & SE & \multicolumn{1}{c|}{$Z$} & $\mathrm{p}$ \\
\hline Intercept & -4.803 & 1.264 & -3.801 & 0.0001 \\
MONTH 8 & 2.786 & 1.210 & 2.302 & 0.0214 \\
MONTH 9 & 2.062 & 1.231 & 1.674 & 0.0941 \\
MONTH 10 & 3.004 & 1.212 & 2.478 & 0.0132 \\
MONTH 11 & 3.318 & 1.255 & 2.644 & 0.0082 \\
MONTH 12 & 5.419 & 1.296 & 4.182 & $<0.0001$ \\
PINGER-INACTIVE & -0.583 & 0.804 & -0.725 & 0.4682 \\
PINGER-ACTIVE & $\mathbf{- 1 . 7 2 5}$ & $\mathbf{0 . 7 1 7}$ & $\mathbf{- 2 . 4 0 5}$ & $\mathbf{0 . 0 1 6 2}$ \\
\hline
\end{tabular}

Full outputs from the model fitting are given in Appendix 1 (available as electronic supplement material at: www.int-res.com/articles/suppl/n005p301_ app.pdf) For both the presence/absence of net interaction and PPUE data, we found that including vessel as a random factor significantly improved model fit over models with only pinger condition as a predictor (Likelihood ratio tests: $\chi^{2}=27.0498, \mathrm{df}=1$ and $\chi^{2}=4181.8$, $\mathrm{df}=1$, for net interaction and PPUE respectively, $\mathrm{p}<$ 0.00001 in both cases; Appendix 1). Previous work showing seasonal effects on both interaction rate and PPUE (Brotons et al. 2007) was confirmed, since models including month as a fixed factor fit significantly better for both response variables than those with only vessel as a random factor and pinger condition as a fixed factor (likelihood ratio tests: $\chi^{2}=42.111$, $\mathrm{df}=5$, $\mathrm{p}<0.00001$ for net interaction and $\chi^{2}=11.248, \mathrm{df}=5$, $\mathrm{p}=0.047$ for PPUE, Appendix 1). Therefore, the final models reported here were all generalised linear mixed models containing month and pinger condition (or a combined condition and pinger brand factor) as fixed factors and vessel as a random factor.

The final models for the presence or absence of evidence of dolphin interaction with the nets showed that there was a significant overall reduction in rates of dolphin-net interactions in active pinger nets $(\mathrm{p}=0.0162$, Table 2), with interaction rates reduced by $49 \%$. However, this reduction was not equal across brands (Fig. 3). While all brands showed some reduction in the active condition compared to the no-pinger control, only the reduction for Aquatec pingers was significant $(p=0.0064$, Table 3$)$. These pingers reduced the net interaction rate by $70 \%$ in active nets.

There were no significant changes in PPUE across treatments, either for experimental conditions overall or when the data were broken down by pinger brand (Tables $4 \& 5$, Figs. $4 \& 5$ ). The presence of pingers, whether active or not, appeared to slightly increase PPUE (e.g. $18 \%$ for the active condition), but this increase was not statistically significant. The largest change relative to the control condition was for inactive SaveWave pingers (a $60 \%$ increase over the control condition), but this was also not statistically significant $(p=0.06)$.

\section{DISCUSSION}

In the present study, the use of active pingers apparently discouraged dolphins from interacting with nets, dramatically so in the case of the Aquatec pingers. Therefore, there is an appar- 


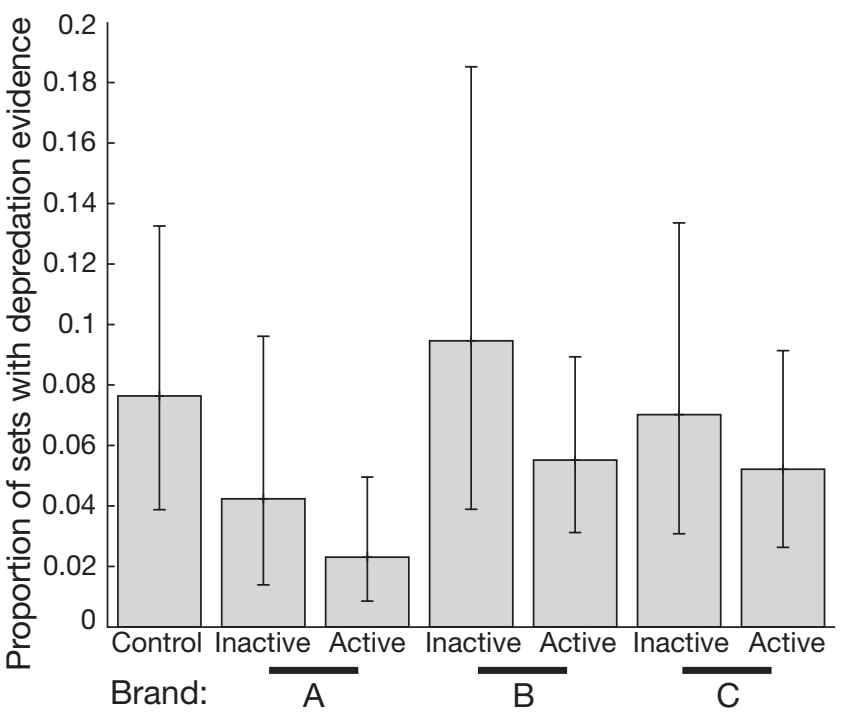

Fig. 3. Interaction rates by treatment and pinger brand $(\mathrm{A}=$ Aquatec, B = Dukane, C = SaveWave). Error bars are 95\% confidence intervals on the maximum likelihood estimates for the binomial probability of net interaction. Active, inactive: status of pingers

Table 3. Coefficients from final model of net interaction with pinger treatment broken down by pinger brand. Here the intercept represents the rate of net interaction in MONTH 7 (July) for the no-pinger control condition. Significant pinger terms are highlighted in bold

\begin{tabular}{|lrrrr|}
\hline Term & Estimate & SE & \multicolumn{1}{c|}{$Z$} & $\mathrm{p}$ \\
\hline Intercept & -4.822 & 1.252 & -3.853 & 0.0001 \\
MONTH 8 & 2.809 & 1.210 & 2.322 & 0.0202 \\
MONTH 9 & 2.090 & 1.227 & 1.703 & 0.0885 \\
MONTH 10 & 3.047 & 1.210 & 2.517 & 0.0118 \\
MONTH 11 & 3.339 & 1.255 & 2.661 & 0.0078 \\
MONTH 12 & 5.465 & 1.294 & 4.225 & $<0.0001$ \\
AQUATEC-INACTIVE & -0.939 & 1.058 & -0.889 & 0.3742 \\
DUKANE-INACTIVE & 0.034 & 1.004 & 0.034 & 0.9732 \\
SAVEWAVE-INACTIVE & -0.881 & 1.018 & -0.865 & 0.3869 \\
AQUATEC-ACTIVE & $\mathbf{- 2 . 7 6 0}$ & $\mathbf{1 . 0 1 2}$ & $\mathbf{- 2 . 7 2 8}$ & $\mathbf{0 . 0 0 6 4}$ \\
DUKANE-ACTIVE & -1.192 & 0.777 & -1.534 & 0.1251 \\
SAVEWAVE-ACTIVE & -1.535 & 0.795 & -1.932 & 0.0533 \\
\hline
\end{tabular}

Table 4. Coefficients from final model of profit per unit effort (PPUE) for overall pinger treatment. Here the intercept represents the PPUE in MONTH 7 (July) for the no-pinger control condition

\begin{tabular}{|lcccc|}
\hline Term & Estimate & SE & $t$ & $\mathrm{p}$ \\
\hline Intercept & 1.210 & 0.156 & 7.571 & 0.0000 \\
MONTH 8 & -0.099 & 0.069 & -1.453 & 0.1466 \\
MONTH 9 & -0.066 & 0.072 & -0.916 & 0.3597 \\
MONTH 10 & -0.140 & 0.073 & -1.917 & 0.0555 \\
MONTH 11 & -0.274 & 0.085 & -3.216 & 0.0013 \\
MONTH 12 & -0.602 & 0.131 & -4.602 & 0.0000 \\
PINGER-INACTIVE & -0.029 & 0.196 & -0.149 & 0.8816 \\
PINGER-ACTIVE & 0.090 & 0.167 & 0.537 & 0.5912 \\
\hline
\end{tabular}

ent case for the further consideration of pingers as a mitigation measure in this fishery. However, it should be noted that we did not document any effects on mortality itself, as we used the frequency of dolphins interacting with nets as a proxy for the risk of entanglement. Therefore, any widespread deployment of pingers in this fishery should be accompanied by careful monitoring of actual mortality levels. Nonetheless, our results suggest that pingers could be an effective ay to reduce bycatch mortality for this fishery.

However, one issue we were not able to address is the possibility of habituation - that the dolphins may, over time, become used to the sounds of pingers once they are widely used (Jefferson \& Curry 1996, Dawson et al. 1998, Cox et al. 2004). Our data come from a single year and only document the initial response to pingers in this fishery. Pingers represented a novel stimulus to the dolphins and we are unable to predict whether and how rapidly they may habituate to these sounds, especially under varying motivational conditions, such as increased hunger if fish stocks become further reduced. If animals learn to associate the pinger sounds with the presence of fish, then the interaction may even be worsened by pinger use (e.g. Bordino et al. 2002). The cognitive abilities of bottlenose dolphins suggest that habituation may occur readily (Whitehead et al. 2004). Therefore, if pingers are to be introduced widely in this fishery, it is essential that their effectiveness be continually monitored.

There are no statistically detectable economic benefits from reduced catch loss and the largest increase in PPUE was seen in the conditions where pingers were inactive. High variability in PPUE within each individual condition effectively swamped any effects that pingers may have been having. The coefficient associated with the active pinger condition suggests that active pingers may increase PPUE by a factor of $\mathrm{e}^{0.09}$, or 1.09 - a $9 \%$ increase, or approximately $€ 300000$ on the 2005 total landed catch value. However, the standard error associated with this parameter (Table 4) suggests that the confidence interval around this estimate is wide. This result does provide perspective on potential benefits of deploying pingers across the whole fishery against the substantial cost of the pingers themselves.

It is also important to consider the issue of statistical power when inter- 
Table 5. Coefficients from final model of profit per unit effort (PPUE) with pinger treatment broken down by pinger brand. Here the intercept represents the PPUE in Month 7 (July) for the no-pinger control condition

\begin{tabular}{|lcccc|}
\hline Term & Estimate & SE & $t$ & $\mathrm{p}$ \\
\hline Intercept & 1.195 & 0.147 & 8.109 & 0.0000 \\
MONTH 8 & -0.087 & 0.069 & -1.270 & 0.2045 \\
MONTH 9 & -0.047 & 0.071 & -0.656 & 0.5120 \\
MONTH 10 & -0.129 & 0.073 & -1.776 & 0.0760 \\
MONTH 11 & -0.258 & 0.086 & -3.008 & 0.0027 \\
MONTH 12 & -0.604 & 0.131 & -4.621 & 0.0000 \\
AQUATEC-INACTIVE & -0.404 & 0.242 & -1.666 & 0.1016 \\
DUKANE-INACTIVE & -0.087 & 0.227 & -0.383 & 0.7016 \\
SAVEWAVE-INACTIVE & 0.472 & 0.247 & 1.911 & 0.0615 \\
AQUATEC-ACTIVE & 0.091 & 0.176 & 0.520 & 0.6050 \\
DUKANE-ACTIVE & 0.173 & 0.173 & 0.997 & 0.3235 \\
SAVEWAVE-ACTIVE & 0.007 & 0.178 & 0.041 & 0.9676 \\
\hline
\end{tabular}

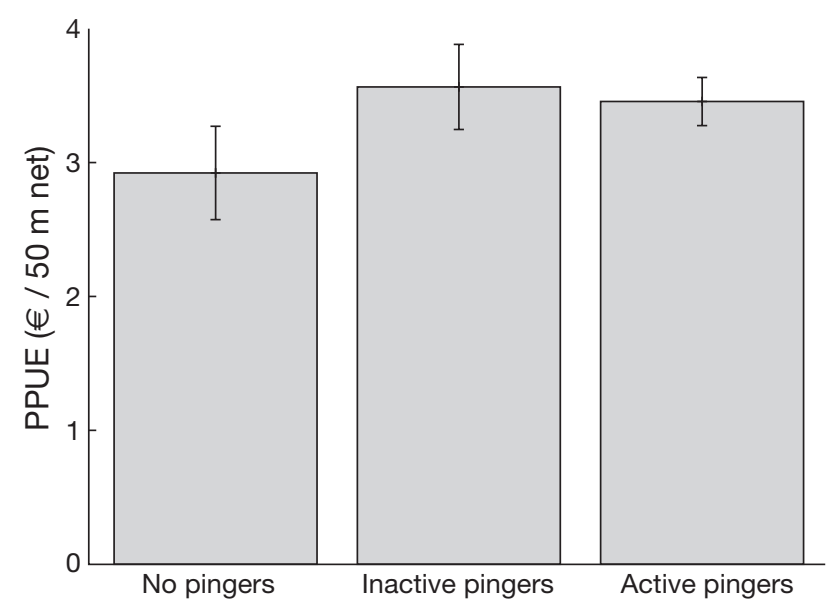

Fig. 4. Profit per unit effort (PPUE) by pinger treatment. Error bars are $95 \%$ confidence intervals assuming normal error

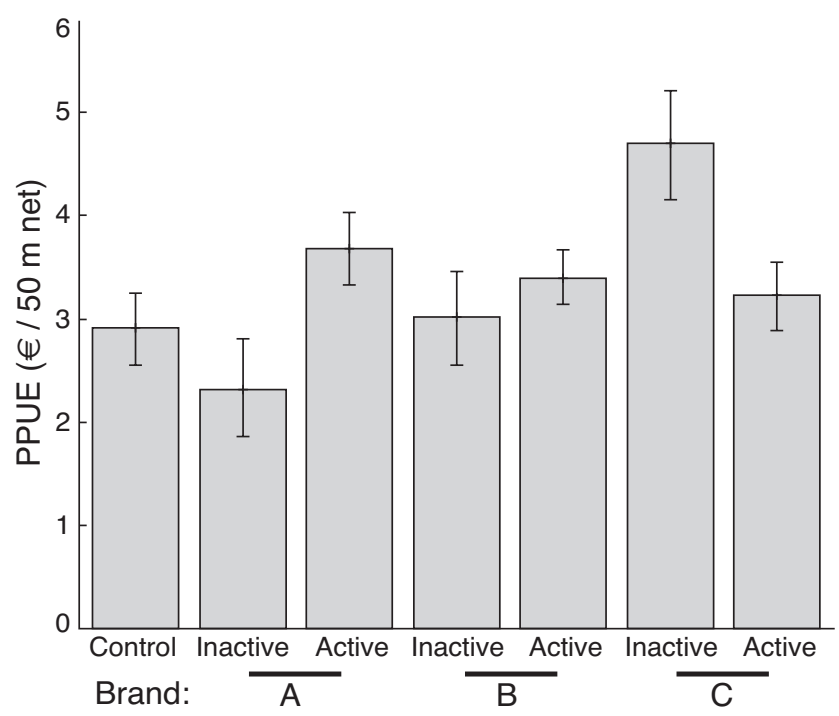

Fig. 5. Profit per unit effort (PPUE) by pinger treatment and brand $(\mathrm{A}=$ Aquatec, $\mathrm{B}=$ Dukane, $\mathrm{C}=$ SaveWave). Error bars are $95 \%$ confidence intervals assuming normal error preting our results. Based on previous research (Brotons et al. 2007), we expected to observe higher rates of dolphin-net interactions; our results here are based on 64 instances of observed evidence of dolphins interacting with nets, with an interaction rate in the absence of pingers of $8.3 \%$ vs. an observed rate of $13 \%$ in previous years. Nonetheless, our study is comparable with other pinger studies; for example Barlow \& Cameron (2003) observed bycatch rates that were similar to the interaction rates in the present study. Furthermore, previous work on statistical power in bycatch mitigation trials suggests that even with reduced interaction rates our study still had reasonable power. Fig. 2 in Dawson et al. (1998) suggests that our sample size, in terms of the number of sets observed, should provide a reasonable power (0.8 to detect a $50 \%$ reduction) for the observed net interaction rate of 0.083 in the control sets, although it should be noted these power calculations assumed a balanced design, which was not the case in our study. However, the issue of detecting statistical significance is secondary to that of estimating the effect size itself, because in the case of bycatch mitigation, 'the magnitude of the required reductions will be so large that simple statistical tests showing small, but significant, results will not be adequate' (Jefferson \& Curry 1996) - a sentiment with which we wholeheartedly agree. More attention needs to be paid to the magnitude of the observed reductions in net interaction rates than to the issue of statistical significance (Johnson 1999). Still, sample sizes must be adequate with respect to the natural variability of the response measure, so we note that the variability inherent in both our response measures is such that future studies of pinger effectiveness will require substantial sampling effort, at least equivalent to that we report here. Of course, the observed effect size should be considered against observed bycatch rates and reduction targets, if they exist. Ideally, results from bycatch mitigation experiments would be compared to baseline bycatch data. Unfortunately, in the present case, there are no robust estimates of the underlying bycatch mortality. Accurate estimates of current mortality rates, along with population size estimates, must be a high priority for ongoing management.

The cost-benefit analysis as to whether pingers are a worthwhile measure for mitigating the interaction between nets and dolphins in these fisheries is an important management consideration. The use of pingers, outside of research such as the present study 
carried out through the Office of Fisheries Management, is currently prohibited in this fishery. We have shown that pingers may have potential as an effective mitigation measure, but our results are not conclusive and additional research must be conducted. If pingers are introduced, long-term study will be absolutely essential to monitor the impact of pingers on mortality levels and to monitor the possibility of habituation and/or sensitisation to the pinger stimuli. Furthermore, the widespread introduction of pingers into this fishery would significantly change the acoustic ecology of Balearic coastal waters, and monitoring the effects of this change on the dolphin population would be important. At this stage, our recommendation is that further trials be conducted to address the habituation issue and that more data be obtained on current bycatch mortality levels to assess how large an impact the artisanal fishery is having on the dolphin population in this area.

Acknowledgements. We thank the participating fishing cooperatives, the captains and crews of the participating vessels and the volunteer observers who collected the data onboard. We also thank W. Hoppit for statistical discussions. Funding for the project was provided by the Government of the Autonomous Community of the Balearics and the European Union (IFOP projects ES.R.BAL.5.1.21/ES.R.BAL.5.1.22). L.R. was supported by a NERC Post-doctoral Fellowship and a Wellcome Trust 'Value in People' award. We thank Simon Northridge and an anonymous reviewer for valuable comments on this manuscript.

\section{LITERATURE CITED}

Barlow J, Cameron GA (2003) Field experiments show that acoustic pingers reduce marine mammal bycatch in the California drift gill net fishery. Mar Mamm Sci 19:265-283

Bordino P, Kraus S, Albareda D, Fazio A, Palmerio A, Mendez M, Botta S (2002) Reducing incidental mortality of Franciscana dolphin Pontoporia blainvillei with acoustic warning devices attached to fishing nets. Mar Mamm Sci 18: 833-842

Brotons JM, Grau AM, Rendell L (2007) Estimating the impact of interactions between bottlenose dolphins and artisanal fisheries around the Balearic Islands. Mar Mamm Sci 24:112-127

Carlström J, Berggren P, Dinnétz F, Börjesson P (2002) A field

Editorial responsibility: Rebecca Lewison,

San Diego, California, USA experiment using acoustic alarms (pingers) to reduce harbour porpoise bycatch in bottom-set gillnets. ICES J Mar Sci 59:816-824

Cox TM, Read AJ, Solow A, Tregenza N (2001) Will harbour porpoises (Phocoena phocoena) habituate to pingers? J Cetacean Res Manag 3:81-86

Cox TM, Read AJ, Swanner D, Urian K, Waples D (2003) Behavioral responses of bottlenose dolphins, Tursiops truncatus, to gillnets and acoustic alarms. Biol Conserv 115:203-212

Culik BM, Koschinski S, Tregenza N, Ellis GM (2001) Reactions to harbor porpoises Phocoena phocoena and herring Clupea harengus to acoustic alarms. Mar Ecol Prog Ser 211:255-260

> Dawson S, Read A, Slooten E (1998) Pingers, porpoises and power: uncertainties with using pingers to reduce bycatch of small cetaceans. Biol Conserv 84:141-146

Faraway JH (2006) Extending the linear model with R: generalized linear, mixed effects and nonparametric regression Models. Chapman \& Hall/CRC, Boca Raton, FL

Fox J (2002) An R and S-Plus Companion to Applied Regression. Sage Publications, Thousand Oaks, CA

Jefferson TA, Curry BE (1996) Acoustic methods of reducing or eliminating marine mammal-fishery interactions: Do they work? Ocean Coast Manag 31:41-70

Johnson DH (1999) The insignificance of statistical significance testing. J Wildl Manag 63:763-772

> Kastelein RA, Jennings N, Verboom WC, de Haan D, Schooneman NM (2006) Differences in the response of a striped dolphin (Stenella coeruleoalba) and a harbour porpoise (Phocoena phocoena) to an acoustic alarm. Mar Environ Res 61:363-378

- Kraus SD, Read AJ, Solow A, Baldwin K, Spradlin T, Anderson E, Williamson J (1997) Acoustic alarms reduce porpoise mortality. Nature 388:525

Leeney RH, Berrow S, McGrath D, O'Brien J, Cosgrove R, Godley BJ (2007) Effects of pingers on the behaviour of bottlenose dolphins. J Mar Biol Assoc UK 87:129-133

> Monteiro-Neto C, Ávila FJC, Alves-Jr TT, Araújo DS and others (2004) Behavioral responses of Sotalia fluviatilis (Cetacea, Delphinidae) to acoustic pingers, Fortaleza, Brazil. Mar Mamm Sci 20:145-151

Perrin WF, Donovan GP, Barlow J (eds) (1994) Gillnets and cetaceans. Rep Int Whaling Comm Spec Issue 15

Pinheiro JC, Bates DM (2000) Mixed-effects models in S and S-PLUS. Springer-Verlag, New York

R Development Core Team (2004) R: A language and environment for statistical computing. R Foundation for Statistical Computing, Vienna, Austria

Whitehead H, Rendell L, Osborne RW, Würsig B (2004) Culture and conservation of non-humans with reference to whales and dolphins: review and new directions. Biol Conserv 120:427-437

Submitted: December 13, 2007; Accepted: May 1, 2008

Proofs received from author(s): July 12, 2008 